BMJ Open

Sport \&

Exercise

Medicine

\title{
Accumulated or continuous exercise for glycaemic regulation and control: a systematic review with meta-analysis
}

\author{
Philip Shambrook, ${ }^{1}$ Michael Kingsley, ${ }^{1}$ Nicholas Taylor, ${ }^{2}$ Brett Gordon ${ }^{1}$
}

\begin{abstract}
To cite: Shambrook $P$, Kingsley M, Taylor N, et al. Accumulated or continuous exercise for glycaemic regulation and control: a systematic review with meta-analysis. BMJ Open Sport \& Exercise Medicine 2018;4:e000470. doi:10.1136/ bmjsem-2018-000470
\end{abstract}

- Additional material is published online only. To view please visit the journal online (http://dx.doi.org/10.1136/ bmjsem-2018-000470).

Accepted 14 November 2018

\section{Check for updates}

(c) Author(s) (or their employer(s)) 2018. Re-use permitted under CC BY-NC. No commercial re-use. See rights and permissions. Published by BMJ.

${ }^{1}$ Discipline of Exercise Physiology, La Trobe Rura Health School, La Trobe University, Bendigo, Victoria, Australia

${ }^{2}$ Department of Rehabilitation, Nutrition and Sport, La Trobe University, Bundoora, Victoria, Australia

Correspondence to Dr Brett Gordon; b.gordon@ latrobe.edu.au

\section{ABSTRACT}

Objective To compare the effectiveness of accumulating exercise in multiple bouts of at least 10 min throughout a day with exercise completed in a single bout (continuous or interval), or no exercise, on glycaemic control and regulation in inactive people without diagnosed glycaemic dysfunction.

Design Systematic review and meta-analysis.

Data sources Seven electronic databases were searched: CINAHL (EBSCO), Cochrane Library, EMBASE (Ovid), MEDLINE 1948-(Ovid), SCOPUS (Elsevier), SPORTDiscus (EBSCO) and Web of Science (ISI) with no restrictions on date and included all titles indexed up to February 2018.

Eligibility criteria for selecting studies Articles reporting insufficiently active adults (19 to 64 years) without metabolic dysfunction, measuring glycaemic control or regulation following at least 6 weeks of aerobic exercise.

Results Only one study compared accumulated exercise to single-bout exercise with no significant effect on fasting glucose $\left(95 \% \mathrm{Cl}:-0.04\right.$ to $\left.0.24 \mathrm{mmol} \cdot \mathrm{L}^{-1}\right)$ or fasting insulin (95\% Cl: -1.79 to $9.85 \mathrm{pmol} \cdot \mathrm{L}^{-1}$ ) reported 48 hours after the final bout. No studies compared accumulated exercise with no-exercise. Compared with no-exercise, single-bout exercise reduces insulin resistance (mean difference (MD): $-0.53 \mathrm{pmol} \cdot \mathrm{L}^{-1} ; 95 \% \mathrm{Cl}:-0.93$ to -0.13$)$. Insulin resistance was clearly reduced with moderate-intensity $(-0.68(-1.28$ to -0.09$))$ but not with high-intensity $(-0.38$ (-1.20 to 0.44$))$ exercise. Single-bout exercise was not statistically more beneficial than no-exercise for glycated haemoglobin $\left(\mathrm{HbA}_{1 \mathrm{c}}\right.$ ) (MD: $-0.11 \% ; 95 \% \mathrm{Cl}$ : -0.24 to 0.02 ) in metabolically healthy individuals.

Summary/conclusion The glycaemic response to accumulated exercise or single-bout exercise might not be different, however exercise intensity might influence the mechanisms generating the response.

PROSPERO registration number CRD42015025042.

\section{INTRODUCTION}

Exercise has long been accepted as an effective method to reduce the risk of developing type 2 diabetes mellitus (T2DM) due to its positive effects on glycaemic regulation and control. ${ }^{1}$ Strong and consistent evidence demonstrates that undertaking at least 30-60 min of moderate to high intensity aerobic exercise
What is already known?

Exercise has a beneficial effect on glucose regulation and control.

- Regular exercise inhibits the progression of glycaemic dysfunction among people without a diagnosed health condition.

What are the new findings?

- Practitioners can prescribe exercise in shorter, multiple bouts per day, however, there is limited evidence for this relating to glucose regulation.

- Exercise should be prescribed at moderate-intensity or high-intensity to regulate glucose for up to 48 hours.

- Exercise must be completed regularly as improvements to glucose regulation might not translate to improved glucose control otherwise.

most davs of the week substantially reduces the risk of developing T2DM. ${ }^{23}$ Consequently, there has been broad adoption of public health guidelines that recommend adults undertake a minimum of $150 \mathrm{~min}$ of moderate-intensity or $75 \mathrm{~min}$ of vigorous-intensity aerobic exercise each week. ${ }^{4-6}$ The guidelines recommend completing exercise in a single bout or accumulating these exercise durations in multiple bouts of at least 10 min throughout a day. ${ }^{4-6}$ However, the guidelines from Australia do not suggest a minimum bout duration, only that at least 150 min of moderate-intensity exercise be accumulated per week. ${ }^{7}$ Either continuous or interval exercise can constitute a single bout of exercise. Despite the recommendations contained in current exercise guidelines, only one review ${ }^{8}$ has summarised the evidence relating to accumulating exercise in multiple shorter bouts. Limited information relating to glycaemic control and regulation was reported, and the majority of studies considered contained exercise programmes of less than 6 weeks in duration.

In addition to T2DM risk reduction, exercise also reduces the risk of developing 
cardiovascular disease, primarily through improved metabolic function. ${ }^{9}$ Exercise-based improvements to glycaemic control and regulation occur via several different and complex pathways involving a range of muscle contraction, regulatory and counter-regulatory biochemical mechanisms. ${ }^{2}$ Muscle contraction-mediated pathways are known to remain active for only a short period following exercise. ${ }^{10}$ Sensitivity to insulin is also increased following exercise, and this insulin-mediated pathway might remain elevated for several days. ${ }^{11}$ Therefore, more frequent bouts of exercise might result in greater amounts of contraction-mediated glucose uptake without interfering with improvements in insulin sensitivity. Concepts of exercise snacking (very short but frequent exercise bouts) ${ }^{12}$ and breaking up sedentary behaviour ${ }^{13}$ have been shown to benefit glycaemic regulation. However, these studies have only investigated the response to one-off or short duration exercise programmes that are unable to provide evidence relating to long-term glycaemic control and regulation. In addition to exercise bout duration, different exercise intensities have been recognised to induce changes to glycaemic control and regulation through different mechanistic pathways. Although all exercise guidelines recommend either (or a combination of) moderate or vigorous exercise intensity, it remains unclear whether the metabolic response to different intensity exercise is different in people without known metabolic dysfunction.

Accumulating aerobic exercise in bouts of at least 10 min throughout a day is beneficial for cardiorespiratory health and fitness, although it might not be more beneficial than completing single-bout aerobic exercise (continuous or interval). ${ }^{14}$ Accumulating exercise in shorter bouts might also be an effective strategy to overcome the frequently cited barrier to exercise, "lack of time" ${ }^{" 15}$ and improve exercise compliance. Although exercise participation and cardiorespiratory fitness might be improved through accumulating exercise, the evidence for this prescription of exercise to improve glycaemic control and regulation has not been adequately reviewed. Before recommending exercise participation in shorter, multiple bouts a day, it is important to collate the evidence and ascertain if changes in glycaemic regulation and control are similar or different to those attained from single-bout exercise.

Therefore, the primary aim of this review and meta-analysis was to identify studies to compare the effects of aerobic exercise, completed in a single bout (continuous or interval) or accumulated in multiple short bouts throughout a day, on glycaemic control and regulation in a young to middle-aged, insufficiently active adult population. The secondary aim was to assess whether exercise completed at different intensities resulted in different glycaemic responses.

\section{METHODS}

This review protocol was prospectively registered with the PROSPERO International register of systematic reviews (registration number CRD42015025042). It is reported in accordance with the Preferred Reporting Items for Systematic Reviews and Meta-Analyses statement. ${ }^{16}$

A systematic literature search of CINAHL (EBSCO), Cochrane Library, EMBASE (Ovid), MEDLINE 1948(Ovid), SCOPUS (Elsevier), SPORTDiscus (EBSCO) and Web of Science (ISI) databases was undertaken with no restrictions on date and included all titles indexed up to February 2018. The PICO approach was used to focus the search on Population (sedentary or inactive adults aged 19 to 64 years); Intervention (any type of aerobic exercise intervention using accumulated, interval or continuous exercise); Comparator (single-bout exercise or no-exercise) and Outcome (measures of glycaemic control or regulation such as glycated haemoglobin $\left(\mathrm{HbA}_{1 c}\right)$, glucose, insulin and indices of insulin sensitivity). Keywords for the search terms, including appropriate $\mathrm{MeSH}$ terms for these constructs, were determined and combined with OR and AND Boolean operators in electronic databases (online supplementary table 1. Titles, abstracts and keywords were searched. Only English language studies and those for which an English language translation was available were included. The search was limited to peer-reviewed studies involving human participants aged 19 to 64 years.

As it was anticipated that a small number of studies would provide direct comparison between accumulated exercise and single-bout exercise, an a priori decision was made to include studies that compared either accumulated aerobic exercise or single-bout aerobic exercise against a no-exercise control. Studies were excluded according to the following criteria: (1) participants consuming medication known to affect glycaemic regulation or diagnosed with a glucose metabolism disorder; (2) participants known to be active or exceeding current guidelines as any changes to measures of glycaemic regulation or control are likely to be minimal; (3) interventions $<6$ weeks duration as the effects of exercise on $\mathrm{HbA}_{1 c}$ are likely to be minimal with short duration exercise programmes; (4) studies that did not include a measure of glycaemic control or glucose regulation; (5) studies with interventions that combined additional interventions with accumulated and/or single-bout exercise; (6) resistance or strength exercise only and (7) reviews, commentaries, editorials, conference abstracts or studies without original data.

Studies were initially excluded by one author (PS) based on title. Two authors (PS, BG, MK, NT) conducted reviews of abstracts independently. In the instance of disagreements between reviewers, a third author (BG, MK, NT) provided a majority decision on whether the article was included for full-text review or excluded. Fulltext review occurred in the same manner as the abstract review. Included studies were further reviewed (PS) to identify randomised controlled trials (RCTs) for inclusion in meta-analyses.

One author (PS) extracted data from identified fulltext studies for the meta-analyses, with the validity of these data checked by another author (BG). Means and 
measures of variance (SD, SE, 95\% CI) relating to the specified outcomes $\left(\mathrm{HbA}_{1 \mathrm{c}}\right.$, plasma glucose, plasma insulin, indices of insulin resistance and insulin sensitivity) were extracted. When required, measures of variance were converted into SD and then entered into RevMan V.5 software for synthesis and analysis. Requests were sent to authors of articles with missing or incomplete data, with studies excluded from those meta-analyses if data were not obtained or verified.

The meta-analysis for glycaemic control $\left(\mathrm{HbA}_{1 \mathrm{c}}\right)$ was stratified by exercise intensity. Fasting glucose, fasting insulin, homeostatic model assessment of insulin resistance (HOMA-IR) and insulin sensitivity index were reported in sufficient numbers to allow meta-analyses for short-term glycaemic regulation 12-24 hours and 36-48 hours after the final exercise bout and were also stratified by exercise intensity. Acute phase insulin secretion, glucose effectiveness, insulin sensitivity index (M value), 1 hour glucose concentration, 1 hour insulin concentration, glucose 2-hour area under the curve (AUC), insulin 2-hour AUC, quantitative insulin sensitivity check index, postprandial glucose concentration and oral glucose insulin sensitivity outcome measures were not reported in sufficient numbers to be subject to meta-analysis, as a minimum, two studies are required. ${ }^{17}$

Studies containing more than one relevant exercise intervention group at the same exercise intensity were combined to create single pairwise comparisons using formulae contained in the Cochrane Handbook for Systematic Reviews of Interventions. ${ }^{17}$ Studies were stratified by exercise intensity into low-intensity, moderate-intensity and high-intensity using criteria from the American College of Sports Medicine. ${ }^{18}$ The standardised mean difference (SMD) or mean difference (MD) with 95\% CI were calculated between interventions from postintervention measures. Meta-analyses for outcomes were created using random effects models where heterogeneity was substantial $\left(\mathrm{I}^{2}>50 \%\right) .{ }^{17}$ Data contained in the meta-analyses were assessed for study and outcome quality using GRADEpro GDT computer software (GRADEpro GDT, McMaster University) by one author (PS) and validated by another (BG). Risk of Bias was assessed using Review Manager V.5.3 computer software (RevMan V.5.3).

\section{RESULTS}

The search strategy identified 5919 unique articles, of which 149 articles met the inclusion criteria (figure 1). Sixteen of the 56 RCTs retrieved were included in meta-analyses (figure 1). Two separate studies reported in one article were treated as separate studies, one of which was included in the meta-analyses. ${ }^{19}$ Duplicated data were not included in meta-analyses if reported in multiple articles from the same study, the available data were incomplete or in a format that could not be used, the control group received an intervention likely to affect the measured outcomes, or when outcomes were measured beyond 48 hours, or not adequately specified, after the final exercise bout (online supplementary table 2). One RCT was identified that directly compared accumulated exercise with single-bout exercise. ${ }^{19}$ Apart from Asikainen $e t a l,{ }^{19}$ zero studies were identified that compared accumulated exercise with no-exercise. Including the no-exercise arm of Asikainen et al, ${ }^{19} 16$ RCTs compared single-bout exercise, either continuous or interval, with no-exercise. ${ }^{19-34}$ The 16 RCTs included in the meta-analyses contained 1133 participants (392 males, 683 females and 58 not identified to a specific sex; table 1). Interventions consisted of 30 to $90 \mathrm{~min}$ of exercise for 3 to 5 days per week over durations between 6 weeks and 12 months. One study included in the meta-analyses assessed glycaemic outcomes 24 hours, 72 hours and 2 weeks following the final exercise bout; only the results at 24 hours were included in meta-analyses. ${ }^{26}$

The single study that compared accumulated exercise and single-bout exercise did not assess glycaemic control. ${ }^{9}$ This single study with 87 female participants compared measures of glycaemic regulation between accumulated exercise $(2 \times 15 \mathrm{~min}$ bouts, 5 days per week at $\left.65 \% \quad \mathrm{VO}_{2 \max }\right)$ and single-bout continuous exercise $\left(1 \times 30\right.$ min bout, 5 days per week at $\left.65 \% \mathrm{VO}_{2 \max }\right)$ approximately 48 hours after the final exercise bout, and reported no significant difference between accumulated (net change $-0.21 \mathrm{mmol} \cdot \mathrm{L}^{-1}, 95 \%$ CI -0.33 to 0.16 ) or single-bout exercise $\left(-0.13 \mathrm{mmol} \cdot \mathrm{L}^{-1},-0.25\right.$ to -0.010$)$ for fasting glucose, or fasting insulin (accumulated: -3.34 $\mathrm{pmol} \cdot \mathrm{L}^{-1},-7.30$ to 0.63 : single-bout: $-2.43 \mathrm{pmol} \cdot \mathrm{L}^{-1},-6.46$ to 1.53). ${ }^{19}$ Compared with the no-exercise control group, there was a reduction in glucose concentration 2 hours after an oral glucose challenge following single-bout exercise $\left(-0.48 \mathrm{mmol} \cdot \mathrm{L}^{-1},-0.89\right.$ to -0.08$)$ and accumulated exercise $\left(-0.43 \mathrm{mmol} \cdot \mathrm{L}^{-1},-0.83\right.$ to -0.02$)$, but no change in insulin concentration.

The evidence comparing single-bout exercise with no-exercise for fasting glucose was of low to moderate quality (18 RCTs, 1058 participants; online supplementary table 3). Fasting glucose was not reduced 12-24 hours after the final exercise bout (10 RCTs, 740 participants, MD: $-0.10 \mathrm{mmol} \cdot \mathrm{L}^{-1}$; $95 \% \mathrm{CI}:-0.22$ to 0.02 ; figure $2 \mathrm{~A}$ ) but was reduced 36-48 hours after the final exercise bout (8 RCTs, 318 participants, MD: $-0.24 \mathrm{mmol} \cdot \mathrm{L}^{-1}$; $95 \%$ CI: -0.45 to -0.04 ; figure $2 \mathrm{~B}$ ). However, in comparison to no-exercise, low-intensity, moderate-intensity or high-intensity exercise did not demonstrate a clear benefit for reducing fasting glucose concentration (figure 2A,B).

The evidence comparing single-bout exercise with no-exercise for fasting insulin was of low to moderate quality (15 RCTs, 1042 participants; online supplementary table 3). Exercise reduced fasting insulin 12-24 hours after the final exercise bout (9 RCTs, 797 participants, MD: $-15.69 \mathrm{pmol} \cdot \mathrm{L}^{-1}$; $95 \%$ CI: -25.06 to -6.33 ; figure 3A) but not 36-48 hours after the final exercise bout (6 RCTs, 245 participants, MD $-11.97 \mathrm{pmol} \cdot \mathrm{L}^{-1}$; 95\% CI: -24.26 to 0.32; figure 3B). High-intensity exercise reduced insulin concentration at both 12-24 hours and 36-48 after the final exercise bout (figure 3A,B). 


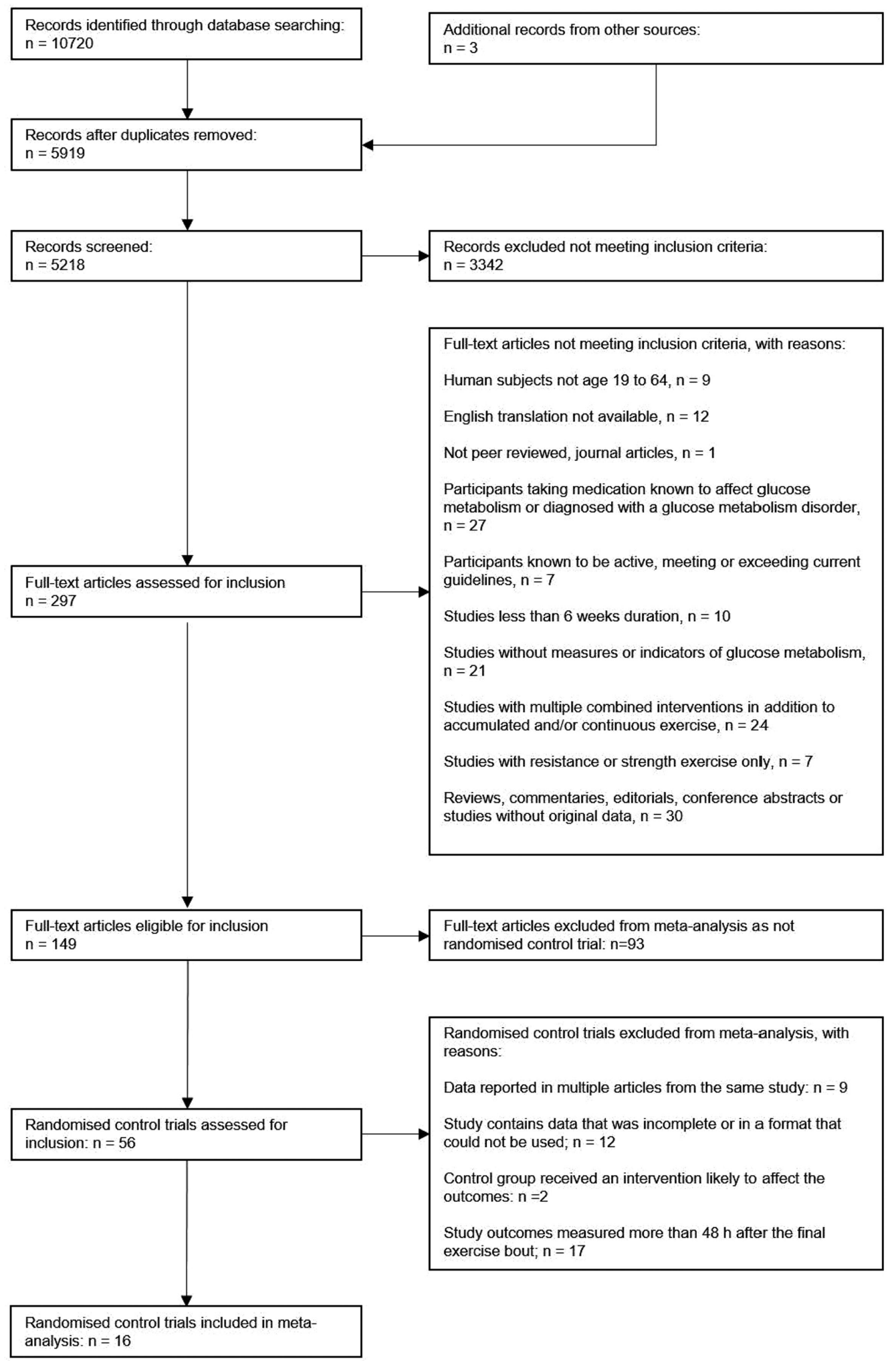

Figure 1 Preferred Reporting Items for Systematic Reviews and Meta-Analyses study flow chart.

However, moderate-intensity exercise only reduced insulin concentration at 12-24 hours after the final exercise bout (figure 3A).

The evidence comparing single-bout exercise with no-exercise for HOMA-IR and insulin sensitivity (using the methods of McAuley et $a l^{35}$ in O'Donovan $e t a l^{30}$ and methods of Bergman $e t a l^{6}$ in Houmard $e t a l^{25}$ ) was of low to moderate quality (online supplementary table 3 ). HOMA-IR (7 RCTs, 493 participants, MD: $-0.53 ; 95 \%$ CI: -0.93 to -0.13 ; figure $4 \mathrm{~A}$ ) and insulin sensitivity (3 studies, 162 participants, SMD $-0.62 ; 95 \%$ CI: 0.12 to 1.12; figure $5 \mathrm{~A}$ ) were improved 12-24 hours after the 


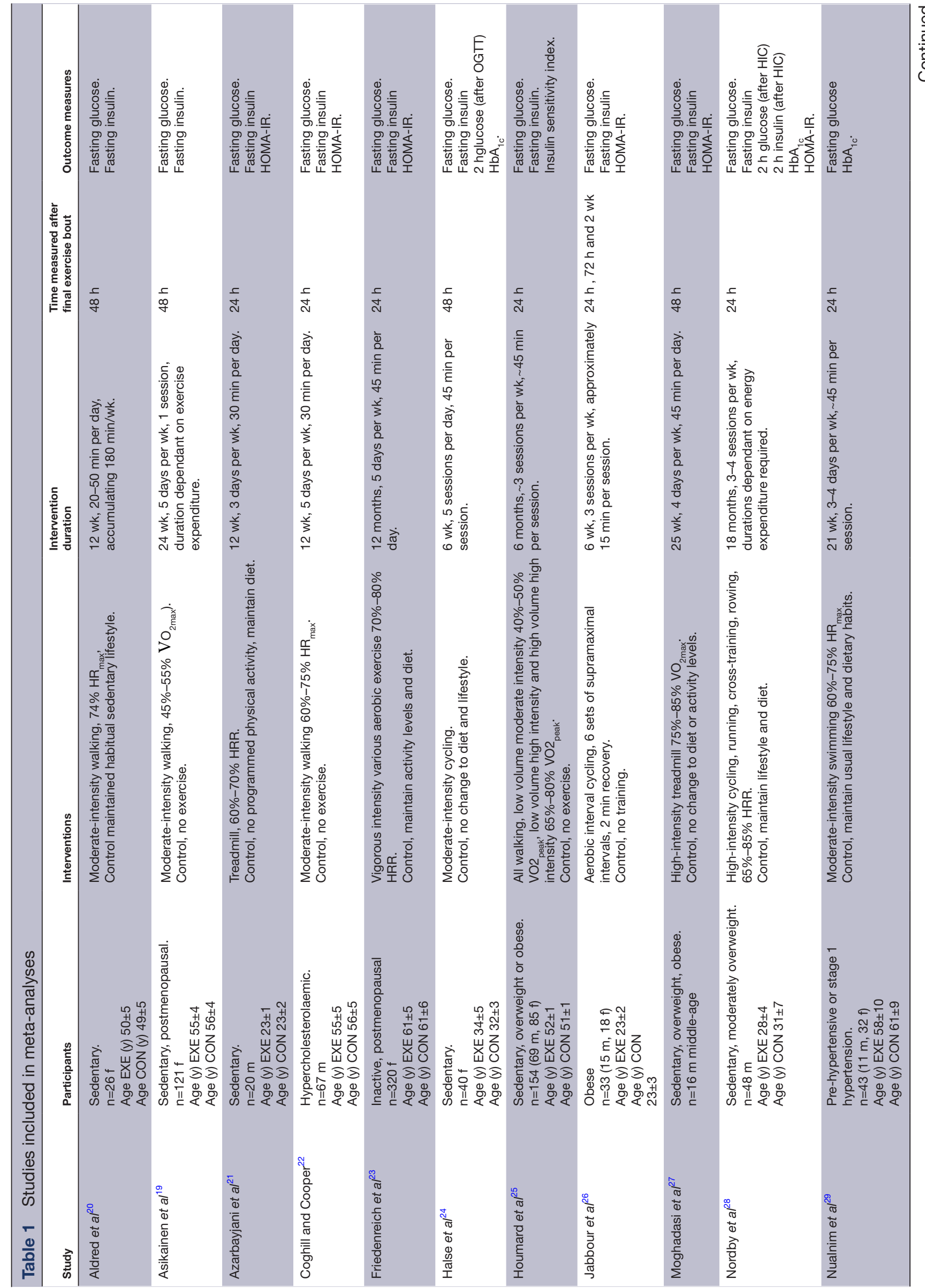




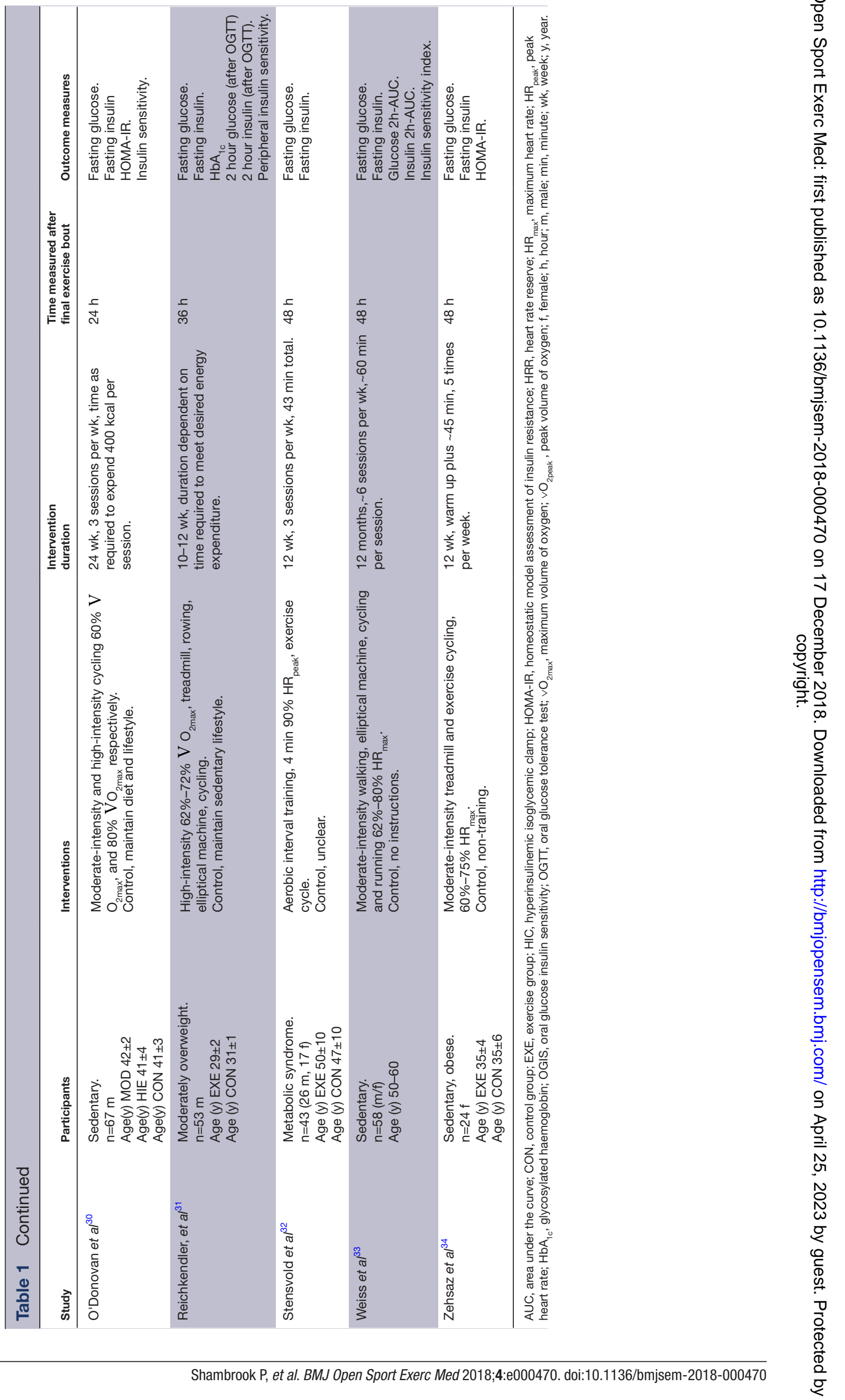


A

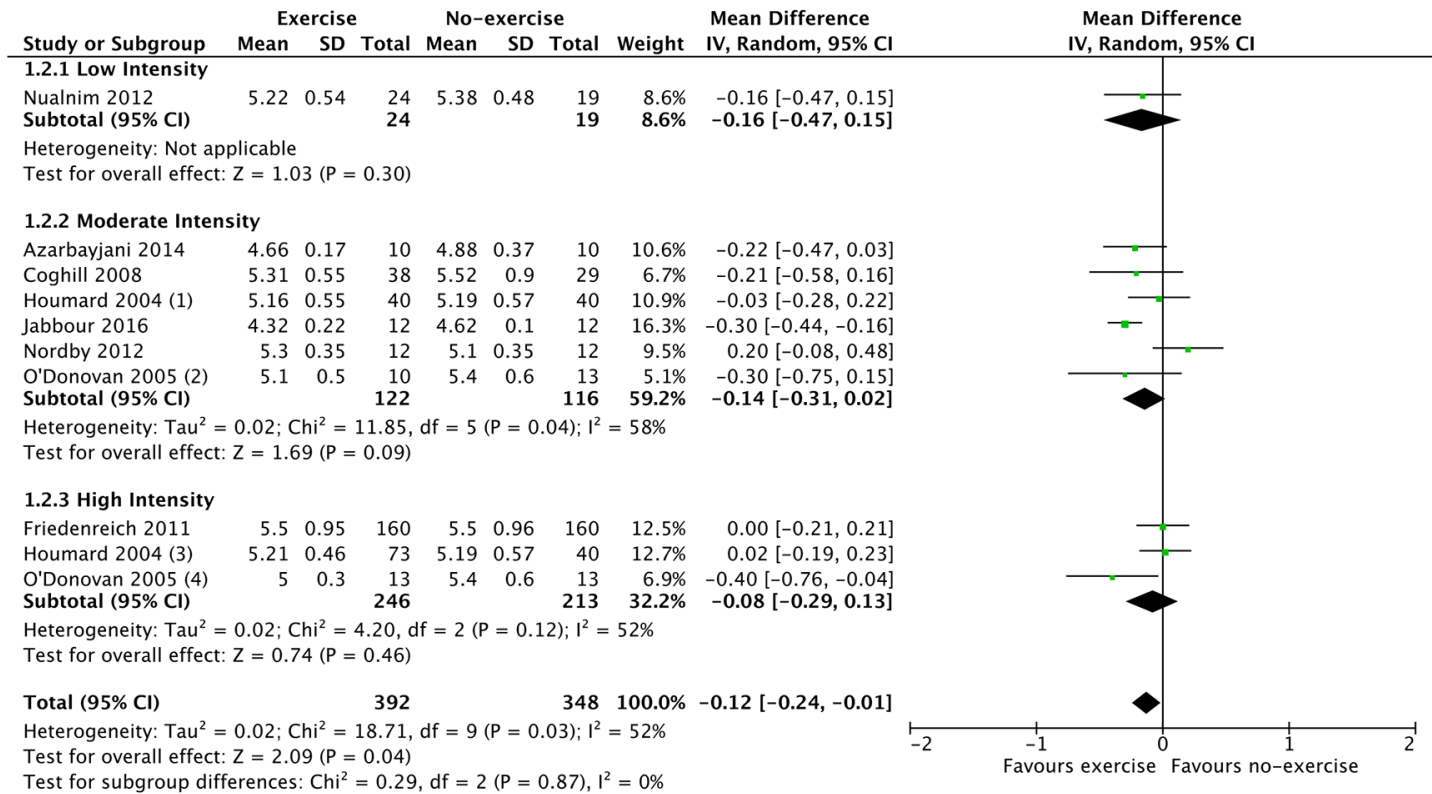

Test for subgroup differences: $\mathrm{Chi}^{2}=0.29, \mathrm{df}=2(\mathrm{P}=0.87), \mathrm{I}^{2}=0 \%$

Footnotes

(1) Low Volume Moderate Intensity only

(2) Moderate intensity exercise at $60 \% \mathrm{VO}_{2 \max }$

(3) Low Volume High Intensity and High Volume High Intensity combined

(4) Vigorous intensity exercise at $80 \% \mathrm{VO}_{2 \max }$

B

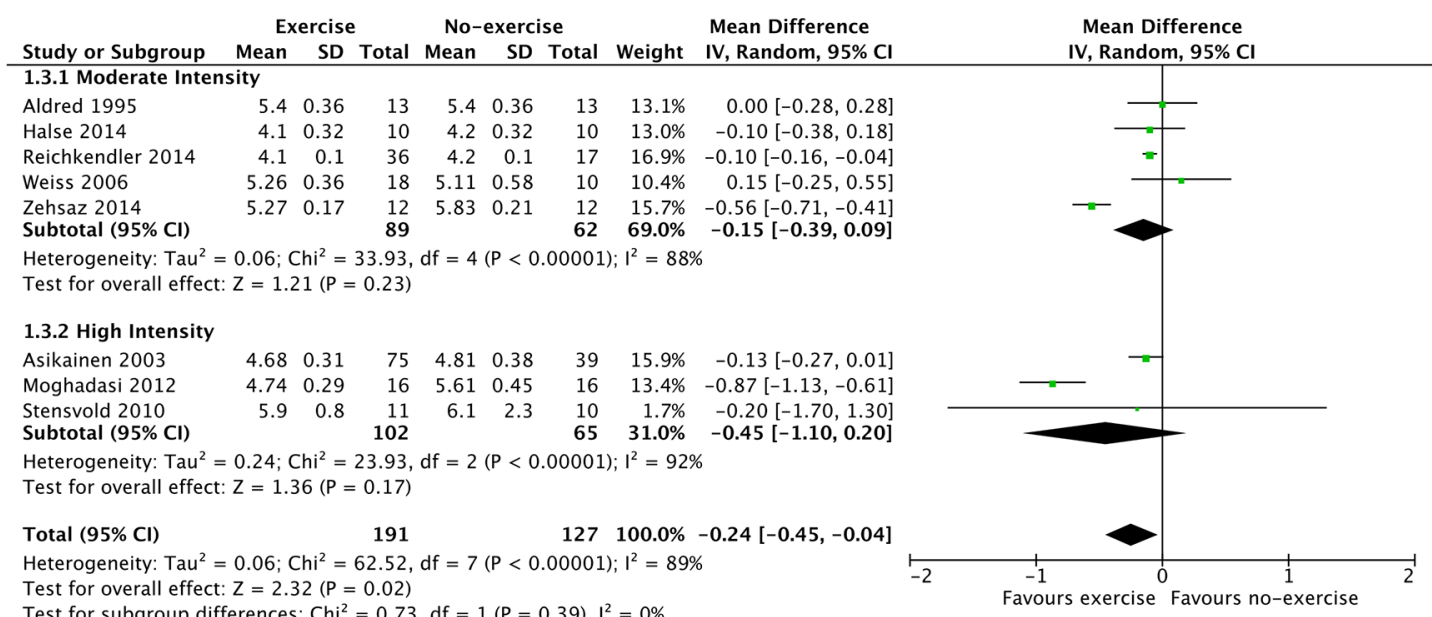

Figure 2 Forest plot stratified by exercise intensity of the fasting glucose response measured (A) up to 24 hours after the final exercise bout and (B) 36-48 hours after the final exercise bout.

final exercise bout. HOMA-IR was also improved 36-48 hours after the final exercise bout (two studies, 56 participants, MD: 1.35 ; $95 \%$ CI: 2.01 to 0.70 ; figure $4 \mathrm{~B}$ ). Moderate-intensity, but not high-intensity exercise benefited insulin resistance (figure 4A), while high-intensity but not moderate-intensity exercise benefited insulin sensitivity (figure 4C) 12-24 hours after exercise. Both moderate-intensity (Zehsaz $e t a l^{34}$ and high-intensity (Moghadasi $e t a l^{27}$ ) exercise showed clear favourable effects for insulin resistance 36-48 hours after the final exercise bout (figure 4B). Single-bout moderate to high-intensity exercise was reported to be beneficial for insulin sensitivity $36-48$ hours following the final exercise bout. $^{33}$

The evidence comparing single-bout exercise with no-exercise for $\mathrm{HbA}_{1 c}$ was of moderate quality (5 RCTs, 182 participants, online supplementary table 4) but failed to demonstrate a clear favourable effect (MD: $-0.11 \%$; $95 \%$ CI: -0.24 to 0.02 ; figure 5 ). Neither moderate nor high-intensity exercise demonstrated differing effects for the reduction of $\mathrm{HbA}_{1 \mathrm{c}}$ (figure 5).

\section{DISCUSSION}

Despite previous calls to increase the evidence base, there remains a lack of evidence to determine whether different 
A

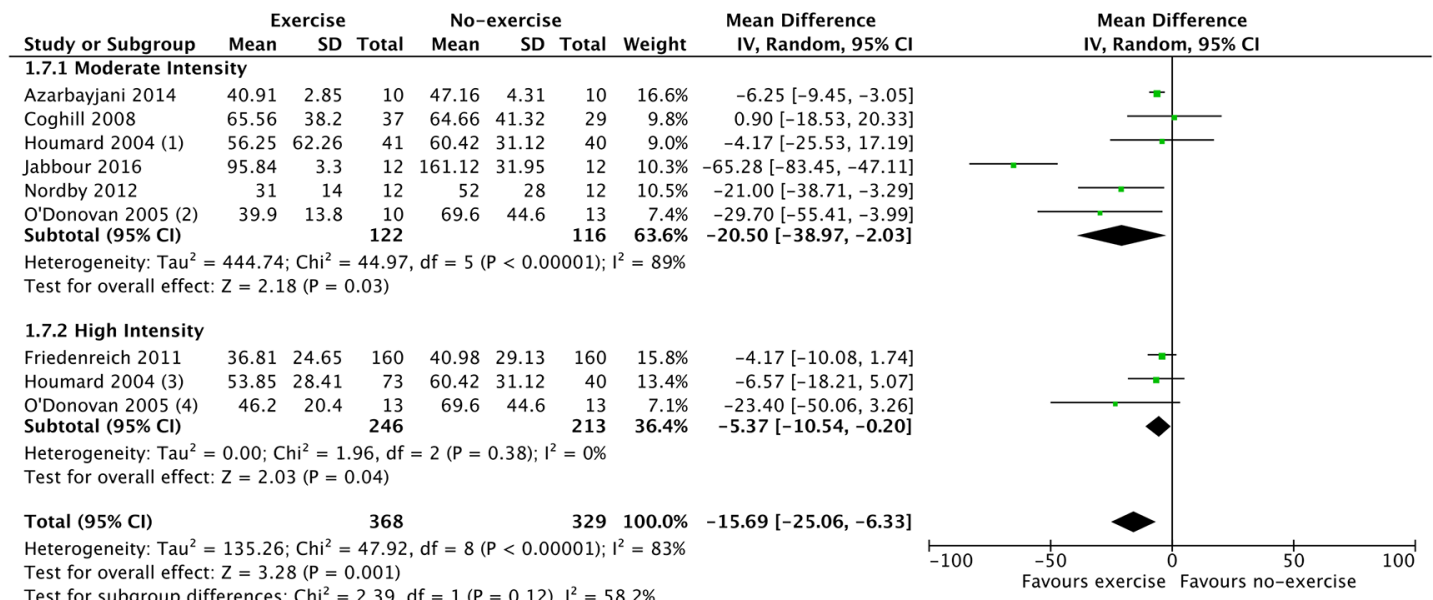

Test for subgroup differences: $\mathrm{Chi}^{2}=2.39, \mathrm{df}=1(\mathrm{P}=0.12), \mathrm{I}^{2}=58.2 \%$

Footnotes

(1) Low Volume Moderate Intensity only

(2) Moderate intensity exercise at $60 \%$ VO

(3) Low Volume High Intensity and High Volume High Intensity combined

(4) High intensity at $80 \% \mathrm{VO}_{2 \max }$

B

\begin{tabular}{|c|c|c|c|c|c|c|c|c|c|c|c|}
\hline \multirow[b]{2}{*}{ Study or Subgroup } & \multicolumn{3}{|c|}{ Exercise } & \multicolumn{3}{|c|}{ No-exercise } & \multicolumn{2}{|r|}{ Mean Difference } & \multirow{2}{*}{\multicolumn{3}{|c|}{$\begin{array}{c}\text { Mean Difference } \\
\text { IV, Random, } 95 \% \mathrm{CI}\end{array}$}} \\
\hline & Mean & SD & Total & Mean & SD & Total & Weight & IV, Random, 95\% CI & & & \\
\hline \multicolumn{12}{|c|}{ 1.9.1 Moderate Intensity } \\
\hline Aldred 1995 & 43.06 & 15 & 13 & 38.89 & 10 & 13 & $17.5 \%$ & $4.17[-5.63,13.97]$ & & 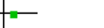 & \\
\hline Weiss 2006 & 38.89 & 25.7 & 18 & 31.25 & 20.14 & 10 & $14.2 \%$ & $7.64[-9.59,24.87]$ & & & \\
\hline $\begin{array}{l}\text { Zehsaz } 2014 \\
\text { Subtotal }(95 \% \mathrm{Cl})\end{array}$ & 73.76 & 15.83 & $\begin{array}{l}12 \\
43\end{array}$ & 93.2 & 14.38 & $\begin{array}{l}12 \\
35\end{array}$ & $\begin{array}{l}16.6 \% \\
48.3 \%\end{array}$ & $\begin{array}{l}-19.44[-31.54,-7.34] \\
-2.93[-19.85,13.99]\end{array}$ & & & \\
\hline \multicolumn{12}{|c|}{$\begin{array}{l}\text { Heterogeneity: } \mathrm{Tau}^{2}=178.81 ; \mathrm{Chi}^{2}=10.61, \mathrm{df}=2(\mathrm{P}=0.005) ; \mathrm{I}^{2}=81 \% \\
\text { Test for overall effect: } \mathrm{Z}=0.34(\mathrm{P}=0.73)\end{array}$} \\
\hline \multicolumn{12}{|l|}{ 1.9.2 High Intensity } \\
\hline Asikainen 2003 & 49.69 & 14.24 & 75 & 56.26 & 18.06 & 39 & $18.7 \%$ & $-6.57[-13.09,-0.05]$ & & & \\
\hline Moghadasi 2012 & 55.42 & 8.06 & 16 & 86.81 & 16.25 & 16 & $17.9 \%$ & $-31.39[-40.28,-22.50]$ & - - & & \\
\hline $\begin{array}{l}\text { Stensvold } 2010 \\
\text { Subtotal }(95 \% \mathrm{Cl})\end{array}$ & 79.73 & 13.89 & $\begin{array}{r}11 \\
102\end{array}$ & 104.38 & 20.84 & $\begin{array}{l}10 \\
65\end{array}$ & $\begin{array}{l}15.1 \% \\
\mathbf{5 1 . 7 \%}\end{array}$ & $\begin{array}{r}-24.65[-39.95,-9.35] \\
-20.48[-38.28,-2.67]\end{array}$ & & & \\
\hline \multicolumn{12}{|c|}{$\begin{array}{l}\text { Heterogeneity: } \mathrm{Tau}^{2}=218.53 ; \mathrm{Chi}^{2}=20.77, \mathrm{df}=2(\mathrm{P}<0.0001) ; \mathrm{I}^{2}=90 \% \\
\text { Test for overall effect: } Z=2.25(\mathrm{P}=0.02)\end{array}$} \\
\hline Total $(95 \% \mathrm{Cl})$ & & & 145 & & & 100 & $100.0 \%$ & $-11.97[-24.26,0.32]$ & & & \\
\hline \multicolumn{9}{|c|}{$\begin{array}{l}\text { Heterogeneity: } \mathrm{Tau}^{2}=199.18 ; \mathrm{Chi}^{2}=40.47, \mathrm{df}=5(\mathrm{P}<0.00001) ; \mathrm{I}^{2}=88 \% \\
\text { Test for overall effect: } \mathrm{Z}=1.91(\mathrm{P}=0.06) \\
\text { Test for subqroup differences: } \mathrm{Chi}^{2}=1.96, \mathrm{df}=1(\mathrm{P}=0.16), \mathrm{I}^{2}=49.0 \%\end{array}$} & $\begin{array}{l}-50 \\
\text { Favours }\end{array}$ & Favour & $\begin{array}{ll}50 & 100 \\
\text {-exercise } & \end{array}$ \\
\hline
\end{tabular}

Figure 3 Forest plot stratified by exercise intensity of the fasting insulin response measured (A) up to 24 hours after the final exercise bout and (B) 36-48 hours after the final exercise bout.

metabolic health effects occur with accumulating exercise in short bouts throughout a day or by completing singlebout exercise in insufficiently active younger adults. Only one study reported a direct comparison for glucose regulation between accumulating exercise in multiple shorter bouts throughout a day and single-bout continuous exercise. ${ }^{19}$ While a number of studies reported beneficial metabolic health effects of single-bout exercise (continuous or interval) compared with no-exercise, no studies were identified comparing accumulated exercise with no-exercise. Thus, it was not possible to supplement the limited direct evidence for the efficacy of accumulated exercise with indirect evidence comparing exercise accumulated in multiple short bouts with a no-exercise control.

Accumulating exercise in shorter bouts throughout a day provided similar benefits to single-bout exercise in the single study identified, although measures of longterm glycaemic control were not assessed. ${ }^{19}$ The two programmes of exercise did not produce significant differences for short-term measures of glycaemic regulation: fasting glucose and insulin, or insulin concentrations following an oral glucose tolerance test. ${ }^{19}$ Only fasting glucose improved with both accumulated and single-bout exercise when compared with a no-exercise control. ${ }^{19}$ This single study did not offer any evidence to determine the efficacy of accumulating exercise in shorter bouts, possibly because the interventions were not sufficiently different to elicit a significantly different outcome. The exercise prescription was to expend $1255 \mathrm{~kJ}$ of energy per day, through either two, 15 min bouts or one, 30 min bout of moderate-intensity walking. Despite the recommendation from Murphy et $a l^{8}$ that the benefits of accumulating exercise in shorter bouts be a focus for future research, evidence for the chronic effects of accumulated exercise on metabolic health outcomes, particularly those related to glycaemic regulation, remain limited, both in quantity and quality. Further investigations of the chronic effects of accumulating exercise in multiple bouts of at least 10 min duration, as recommended in current guidelines, ${ }^{5}$ 
A

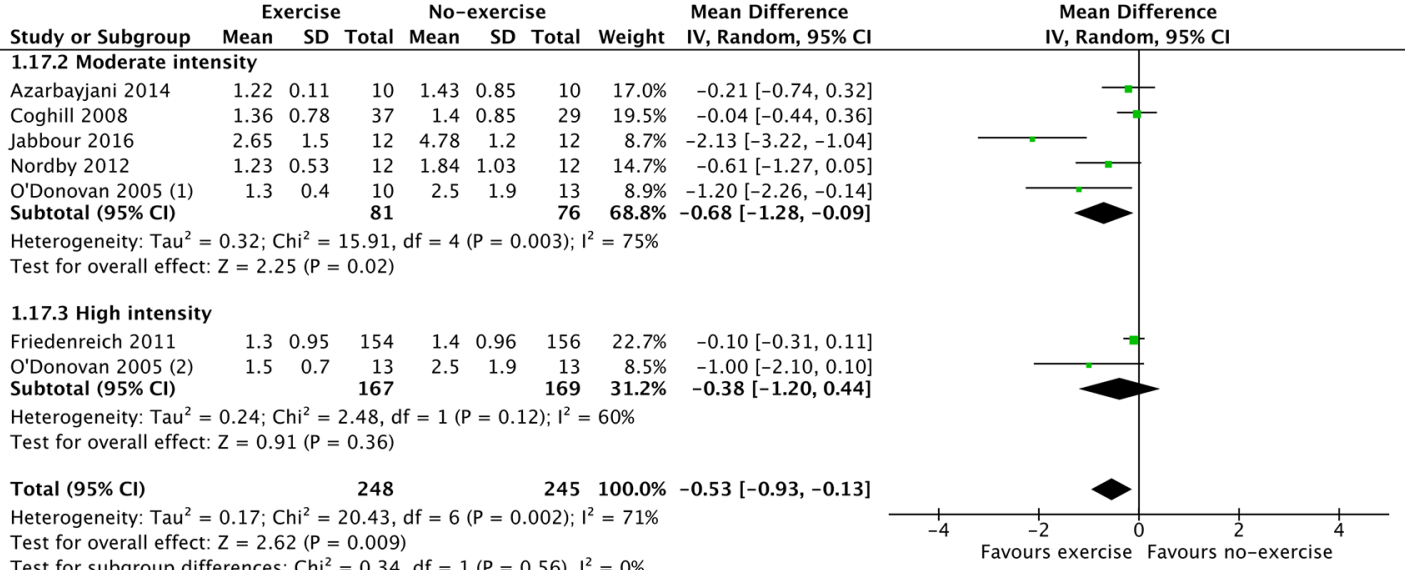

Test for subgroup differences: $\mathrm{Chi}^{2}=0.34, \mathrm{df}=1(\mathrm{P}=0.56), \mathrm{I}^{2}=0 \%$

Favours exercise Favours no-exercise

Footnotes

(1) Moderate intensity exercise at $60 \% \mathrm{VO}_{2 \max }$

(2) High intensity exercise at $80 \% \mathrm{VO}_{2 \max }$

B

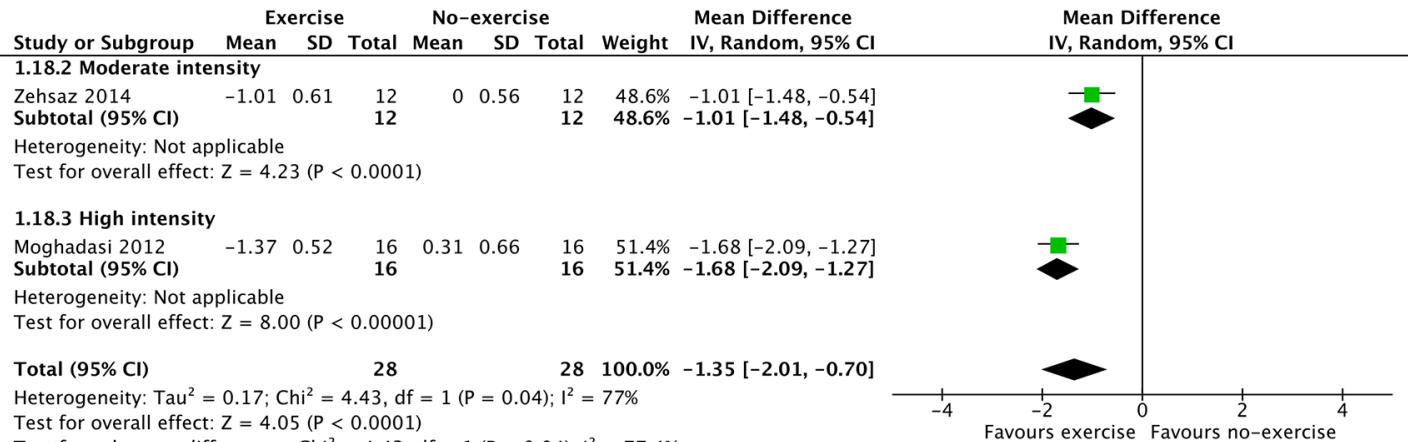

Test for subgroup differences: $\mathrm{Chi}^{2}=4.43, \mathrm{df}=1(\mathrm{P}=0.04), \mathrm{I}^{2}=77.4 \%$

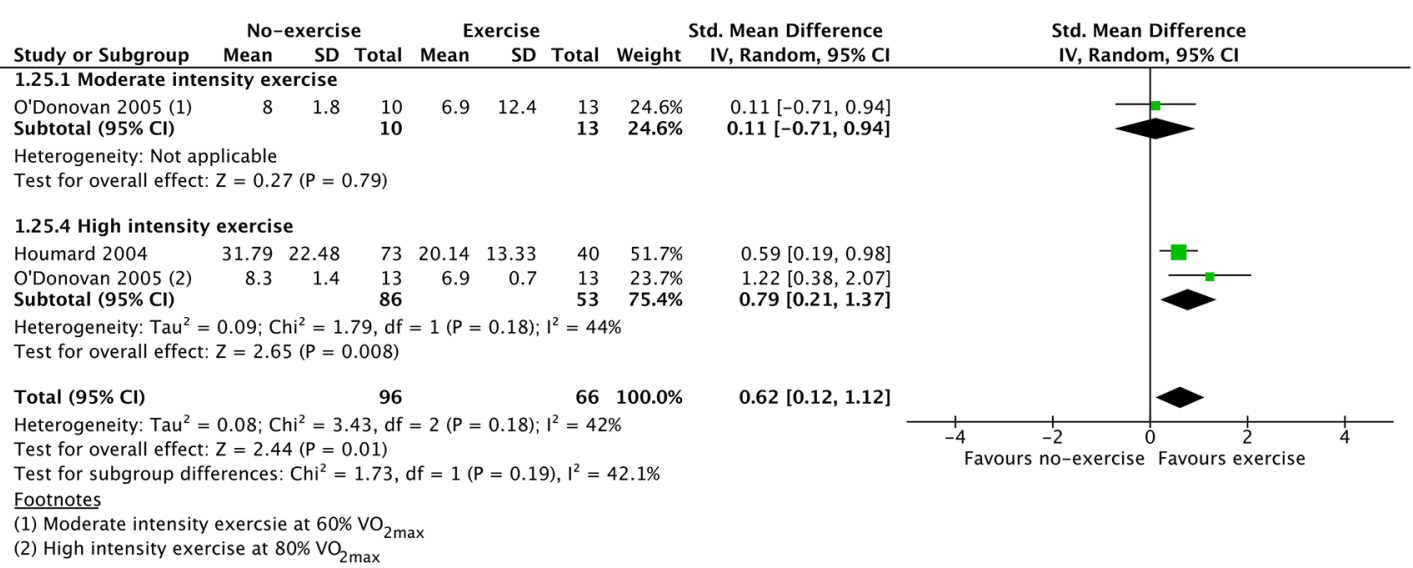

Figure 4 Forest plot stratified by exercise intensity of HOMA-IR measured (A) up to 24 hours after the final exercise bout and (B) 36-48 hours after the final exercise bout and (C) insulin sensitivity measured up to 24 hours after the final exercise bout.

are required to provide evidence-based information for public health advocates and the wider public.

The therapeutic benefit of aerobic exercise for glycaemic control is likely to occur in people without diagnosed metabolic disease, despite the limitations in the quality of these data. Although not statistically significant, the outcome from this meta-analysis suggests that $\mathrm{HbA}_{1 \mathrm{c}}$ can beneficially change in people without established T2DM. Aerobic exercise is accepted to reduce
$\mathrm{HbA}_{1 \mathrm{c}}$ by approximately $0.7 \%$ in people with T2DM and generally poor glycaemic control. ${ }^{37}$ Relatively small reductions in $\mathrm{HbA}_{1 \mathrm{c}}$ (of approximately $1 \%$ ) substantially reduces diabetes-related mortality in people with T2DM. ${ }^{38}$ Similarly, in a previous meta-analysis of participants with and without diabetes, a weighted mean reduction of $0.28 \%$ for $\mathrm{HbA}_{1 c}$ along with improvements to insulin resistance were identified following exercise compared with no-exercise. ${ }^{9}$ This meta-analysis of only 


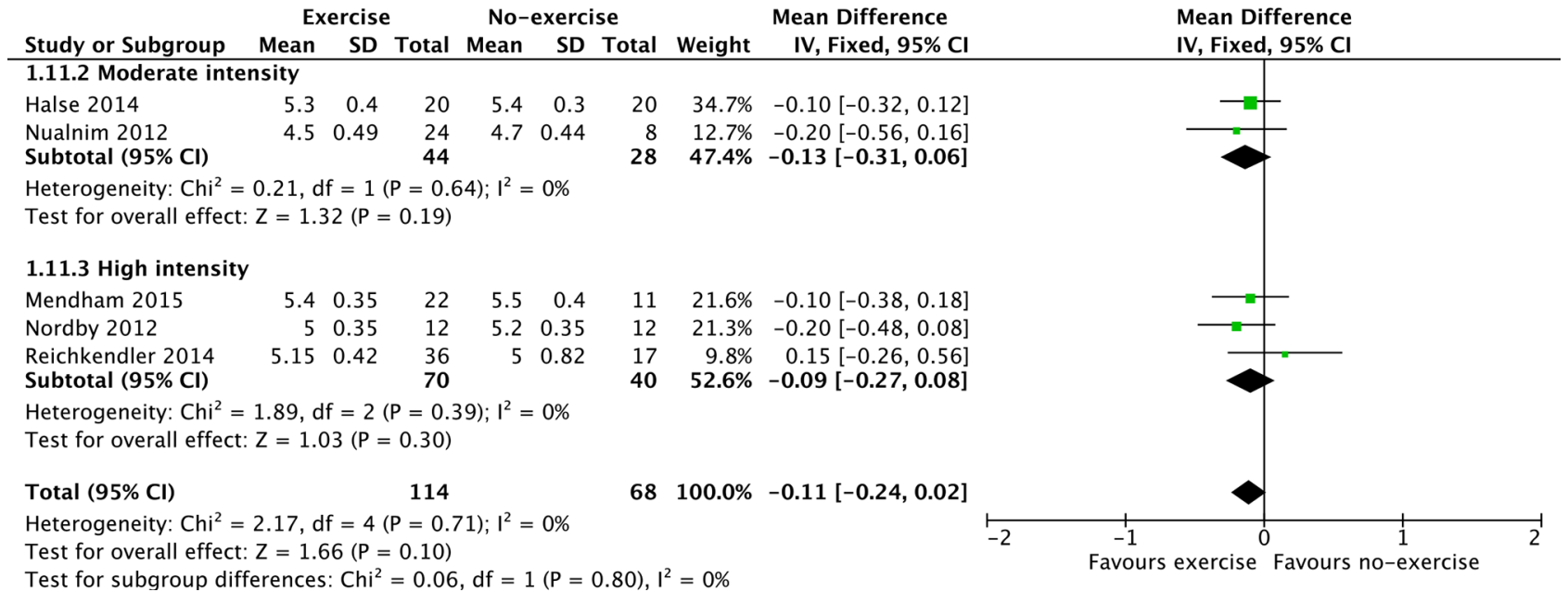

Figure 5 Forest plot stratified by exercise intensity of $\mathrm{HbA} 1_{\mathrm{c}}$.

individuals without metabolic dysfunction has identified a mean reduction in $\mathrm{HbA}_{1 \mathrm{c}}$ of $0.11 \%$. Since the risk of developing cardiovascular disease and diabetes rises concomitantly with any increase in glycaemic levels above normal, ${ }^{39}$ any improvement to glucose metabolism following exercise will contribute to reduced risk for individuals without known metabolic health dysfunction. Interestingly, the meta-analyses conducted from this review failed to produce evidence of a clear difference in response between moderate-intensity and high-intensity exercise. High-intensity interval training compared with continuous exercise training (mostly conducted at moderate intensity) has been reported to reduce insulin resistance, suggesting that intensity might be important. ${ }^{40}$ It has been purported that greater intensity exercise delivers improved metabolic regulation, however the evidence base for this is poor. ${ }^{41}$ In contrast, at least for individuals with T2DM, exercise frequency rather than exercise intensity seems to be important for improving glycaemic control. ${ }^{42}$

The complexity of glucose transport suggests that the response to moderate-intensity or high-intensity exercise probably occurs via different mechanistic pathways. This might account for the similarity in outcomes between the different exercise intensities identified in this meta-analysis. The prescription for moderate-intensity continuous exercise in the included studies ranged from $60 \%$ to $75 \% \mathrm{HR}_{\max }$ (or equivalent measures). Muscle contraction-stimulated glucose uptake is the main mechanism responsible for regulating glucose during moderate-intensity exercise and can occur despite depressed concentrations of insulin. ${ }^{43}$ The prescription for continuous high-intensity exercise in the included studies was relatively consistent, ranging from $80 \%$ to $85 \% \mathrm{HR}_{\text {max }}$. Studies involving interval protocols utilised high-intensity workloads of $80 \%-90 \%$ of $\mathrm{HR}_{\max }$ (or equivalent measures) or bouts of undefined supramaximal intensity. ${ }^{26} 324445$ During high-intensity exercise, the increased catecholamine secretion signals a rapid hepatic glucose response. ${ }^{43}$ Furthermore, since the individuals involved in the studies were insufficiently active, young to middle-aged adults with baseline $\mathrm{HbA}_{1 \mathrm{c}}$ levels between the accepted healthy levels of $4.5 \%$ to $6.0 \%$, only small (potentially not statistically significant) changes would be expected in response to exercise. Small statistically significant reductions in $\mathrm{HbA}_{1 \mathrm{c}}$ of between $0.01 \%$ and $0.04 \%$ occur with every additional week of exercise in individuals with T2DM. ${ }^{37}$ Furthermore, since a $1 \%$ reduction in $\mathrm{HbA} 1_{c}$ is associated with a $37 \%$ reduction in the development of macrovascular complications among people with $\mathrm{T} 2 \mathrm{DM},{ }^{39}{ }^{46}$ this might suggest the mean change of $0.11 \%$ in the population included in this meta-analysis is clinically meaningful to reduce the risk of developing conditions such as T2DM.

This meta-analysis identified no significant effect on fasting glucose concentration up to 24 hours following the final exercise bout, although significant reductions to fasting insulin concentration occurred in the same period. This indicates that in response to exercise training, maintenance of glucose concentration occurs with a lower insulin requirement. Being able to maintain glucose concentrations with less insulin suggests improved insulin sensitivity, which various indices of insulin resistance and insulin sensitivity confirmed up to 48 hours following the final exercise bout. Although contraction-mediated glucose uptake effects are only likely to persist for a short time following exercise, ${ }^{10}$ insulin-dependent glucose uptake can persist for up to 10 days. ${ }^{11}$ The outcomes from the meta-analyses conducted, suggest improved glucose regulation with exercise at both 12-24 hours and 36-48 hours after exercise; although of interest was the difference between moderate-intensity and high-intensity at 12-24 hours after the final exercise bout. Moderate-intensity exercise seemed to reduce insulin resistance, while high-intensity exercise increased insulin sensitivity. The initial difference did not persist though, with both moderate-intensity and high-intensity exercise improving insulin resistance and insulin sensitivity 36-48 hours after the final session. This evidence needs to be interpreted cautiously though, 
as no studies measured glucose regulation at both time points, and few studies evaluated insulin sensitivity 36-48 hours after the final exercise bout. Regardless, the findings might suggest that aerobic exercise needs to be completed at least every second day, with data from Davey and colleagues reporting insulin sensitivity was increased 24 hours after the final session but had returned to near normal levels after 5 days. ${ }^{47}$ This of course might be dependent on the mode and/or intensity of exercise. While no change was reported for glycaemic regulation following continuous exercise at $\sim 75 \% \quad \mathrm{VO}_{2 \text { peak }}$ either 24 hours or 14 days following the final exercise bout, ${ }^{48}$ significant improvements were reported 24 hours and 14 days after the final supramaximal intensity interval training exercise bout. ${ }^{26}$ It is possible that the inherent differences of exercise intensity and session duration are significant contributing factors to changes in glycaemic control and regulation. Along with the broad variations in exercise intensity noted, the duration of each exercise session also ranged from $30 \mathrm{~min}$ to $90 \mathrm{~min}$. Longer duration exercise provides the opportunity for an increased number of muscle contractions, and thus possibly greater energy requirements, which might lead to greater glucose uptake.

The evidence presented in this review is of low-to-moderate quality largely due to randomisation methods not clearly outlined, or difficulties in blinding participants and assessors. Additionally, wide variations in the exercise interventions employed in terms of frequency, intensity, time and type contributed to substantial levels of heterogeneity. Despite the growing interest in high-intensity interval training, only four studies have implemented this type of intervention for at least 6 weeks with the purpose of improving metabolic health in people without metabolic health dysfunction. ${ }^{26} 324445$ Interval training is an area of exercise prescription that guidelines have not yet adequately considered and presents an opportunity for new investigation. The lack of consistent outcome measures also meant that only 16 of 56 RCT studies were able to be included in some of the meta-analyses. Opportunities exist for future research to use a more standardised approach to determine how best to accumulate exercise in multiple bouts throughout a day to improve or prevent the decline of metabolic function among individuals without known metabolic dysfunction. However, this requires broad agreement on individual components of the exercise prescription; frequency, intensity, time and type.

\section{CONCLUSION}

It is uncertain whether exercise accumulated throughout a day is as, or more, effective than single-bout exercise to reduce the risk of developing metabolic disease in insufficiently active, young to middle-aged adults. However, based on the findings from a single study, it might not be worse. This review supports the general observation that glycaemic control (as measured by $\mathrm{HbA}_{1 c}$ ) improves with at least 30 min of continuous exercise, even among adults with glycaemic control below the diagnostic threshold for T2DM. It is not clear whether exercise training programmes provide additive effects on glycaemic regulation, as outcomes are only regularly measured up to 48 hours after the final exercise bout. Regular single bouts of exercise, whether of moderate-intensity or high-intensity, have a clear benefit for regulating glucose for up to 48 hours after the final exercise bout, despite potentially inducing different degrees of glycaemic control.

Acknowledgements The authors would like to thank Paul Xanthos who provided technical support for the project.

Contributors PS, MIK, NT, BAG: contributed to the development of the research questions, study design and literature search strategy. PS: conducted the literature search. PS, MIK, NT, BAG: reviewed articles and performed study selection. PS, BG: performed methodological quality assessment and data extraction. PS, MIK, NT, BAG: contributed to data interpretation. PS: drafted the manuscript. MIK, NT, BAG: provided critical review. All authors read and approved the final manuscript.

Funding PS was supported by an Australian Government Research Training Program Scholarship. The authors have not declared any other grant from any funding agency in the public, commercial or not-for-profit sectors.

Competing interests None declared.

Patient consent Not required.

Provenance and peer review Not commissioned; internally peer reviewed.

Open access This is an open access article distributed in accordance with the Creative Commons Attribution Non Commercial (CC BY-NC 4.0) license, which permits others to distribute, remix, adapt, build upon this work non-commercially, and license their derivative works on different terms, provided the original work is properly cited, appropriate credit is given, any changes made indicated, and the use is non-commercial. See: http://creativecommons.org/licenses/by-nc/4.0/

\section{REFERENCES}

1. Sigal RJ, Kenny GP, Wasserman DH, et al. Physical activity/exercise and type 2 diabetes. Diabetes Care 2006;29:1433.

2. Aune D, Norat T, Leitzmann M, et al. Physical activity and the risk of type 2 diabetes: a systematic review and dose-response metaanalysis. Eur J Epidemiol 2015;30:529-42.

3. Knowler WC, Barrett-Connor E, Fowler SE, et al. Reduction in the incidence of type 2 diabetes with lifestyle intervention or metformin. N Engl J Med 2002;346:393-403.

4. Davies S, Burns H, Jewell T. Start active, stay active: a report on physical activity from the four home countries. United Kingdom, 2011: 1-62.

5. US Department of Health and Human Services. Physical activity guidelines for Americans. 2008. Washington DC, 2008.

6. American Diabetes Association. Standards of medical care in diabetes-2014. Diabetes Care 2014;37 Suppl 1:S14-80.

7. Department of Health, 2014. Australia's physical activity and sedentary behaviour guidelines. secondary australia's physical activity and sedentary behaviour guidelines [resource]. Available from: http://www.health.gov.au/internet/main/publishing.nsf/ Content/health-pubhlth-strateg-phys-act-guidelines

8. Murphy $\mathrm{MH}$, Blair SN, Murtagh EM. Accumulated versus continuous exercise for health benefit: a review of empirical studies. Sports Med 2009;39:29-43.

9. Lin X, Zhang X, Guo J, et al. Effects of exercise training on cardiorespiratory fitness and biomarkers of cardiometabolic health: a systematic review and meta-analysis of randomized controlled trials. $J$ Am Heart Assoc 2015;4:e002014.

10. Hawley JA, Gibala MJ. Exercise intensity and insulin sensitivity: how low can you go? Diabetologia 2009;52:1709-13.

11. Ivy JL. Role of exercise training in the prevention and treatment of insulin resistance and non-insulin-dependent diabetes mellitus. Sports Med 1997;24:321-36.

12. Francois ME, Baldi JC, Manning PJ, et al. 'Exercise snacks' before meals: a novel strategy to improve glycaemic control in individuals with insulin resistance. Diabetologia 2014;57:1437-45.

13. Dunstan DW, Kingwell BA, Larsen R, et al. Breaking up prolonged sitting reduces postprandial glucose and insulin responses. Diabetes Care 2012;35:976-83. 
14. DeBusk RF, Stenestrand U, Sheehan M, et al. Training effects of long versus short bouts of exercise in healthy subjects. Am J Cardiol 1990;65:1010-3.

15. Thomas N, Alder E, Leese GP. Barriers to physical activity in patients with diabetes. Postgrad Med J 2004;80:287-91.

16. Moher D, Liberati A, Tetzlaff J, et al. Preferred reporting items for systematic reviews and meta-analyses: the PRISMA statement. Ann Intern Med 2009;151:264-9.

17. Higgins JPT, Green S, 2011. Cochrane handbook for systematic reviews of interventions. Available from: http://handbook.cochrane. org [Accessed Mar 2011]

18. Pescatello LS, Arena R, Thompson PD. ACSM's guidelines for exercise testing and prescription. 9th edn. Baltimore MD: Wolters Kluwer Health, 2013.

19. Asikainen TM, Miilunpalo S, Kukkonen-Harjula K, et al. Walking trials in postmenopausal women: effect of low doses of exercise and exercise fractionization on coronary risk factors. Scand J Med Sci Sports 2003;13:284-92.

20. Aldred HE, Hardman AE, Taylor S. Influence of 12 weeks of training by brisk walking on postprandial lipemia and insulinemia in sedentary middle-aged women. Metabolism 1995;44:390-7.

21. Azarbayjani MA, Abedi B, Peeri M. Effects of combined aerobic and resistant training on lipid profile and glycemic control in sedentary men. Int Med J 2014;21:132-6.

22. Coghill N, Cooper AR. The effect of a home-based walking program on risk factors for coronary heart disease in hypercholesterolaemic men. A randomized controlled trial. Prev Med 2008;46:545-51.

23. Friedenreich CM, Neilson HK, Woolcott CG, et al. Changes in insulin resistance indicators, IGFs, and adipokines in a year-long trial of aerobic exercise in postmenopausal women. Endocr Relat Cancer 2011;18:357-69.

24. Halse RE, Wallman KE, Newnham JP, et al. Home-based exercise training improves capillary glucose profile in women with gestational diabetes. Med Sci Sports Exerc 2014:46:1702-9.

25. Houmard JA, Tanner CJ, Slentz CA, et al. Effect of the volume and intensity of exercise training on insulin sensitivity. J Appl Physiol 2004;96:101-6.

26. Jabbour G, Mauriege P, Joanisse D, et al. Effect of supramaximal exercise training on metabolic outcomes in obese adults. J Sports Sci 2017;35:1975-81.

27. Moghadasi M, Mohebbi H, Rahmani-Nia F, et al. High-intensity endurance training improves adiponectin mRNA and plasma concentrations. Eur J Appl Physiol 2012;112:1207-14.

28. Nordby P, Auerbach PL, Rosenkilde M, et al. Endurance training per se increases metabolic health in young, moderately overweight men. Obesity 2012;20:2202-12.

29. Nualnim N, Parkhurst K, Dhindsa M, et al. Effects of swimming training on blood pressure and vascular function in adults $>50$ years of age. Am J Cardiol 2012;109:1005-10.

30. O'Donovan G, Kearney EM, Nevill AM, et al. The effects of 24 weeks of moderate- or high-intensity exercise on insulin resistance. Eur $J$ Appl Physiol 2005;95-522-8.

31. Reichkendler MH, Rosenkilde M, Auerbach PL, et al. Only minor additional metabolic health benefits of high as opposed to moderate dose physical exercise in young, moderately overweight men. Obesity 2014;22:1220-32.
32. Stensvold D, Tjønna AE, Skaug EA, et al. Strength training versus aerobic interval training to modify risk factors of metabolic syndrome. J Appl Physiol 2010;108:804-10.

33. Weiss EP, Racette SB, Villareal DT, et al. Improvements in glucose tolerance and insulin action induced by increasing energy expenditure or decreasing energy intake: a randomized controlled trial. Am J Clin Nutr 2006;84:1033-42.

34. Zehsaz F, Farhangi N, Mirheidari L. The effect of aerobic training on CXL5, tumor necrosis factor $\alpha$ and insulin resistance index (HOMA-IR) in sedentary obese women. Cent Eur J Immunol 2014;39:365-9.

35. McAuley KA, Williams SM, Mann JI, et al. Diagnosing insulin resistance in the general population. Diabetes Care 2001;24:460-4.

36. Bergman RN, Finegood DT, Ader M. Assessment of insulin sensitivity in vivo. Endocr Rev 1985;6:45-86.

37. Grace A, Chan E, Giallauria F, et al. Clinical outcomes and glycaemic responses to different aerobic exercise training intensities in type Il diabetes: a systematic review and meta-analysis. Cardiovasc Diabetol 2017;16:37.

38. Karyekar CS, Frederich R, Ravichandran S. Clinically relevant reductions in $\mathrm{HbA1c}$ without hypoglycaemia: results across four studies of saxagliptin. Int J Clin Pract 2013;67:759-67.

39. Stratton IM, Adler Al, Neil HA, et al. Association of glycaemia with macrovascular and microvascular complications of type 2 diabetes (UKPDS 35): prospective observational study. BMJ 2000;321:405-12.

40. Jelleyman C, Yates T, O'Donovan G, et al. The effects of highintensity interval training on glucose regulation and insulin resistance: a meta-analysis. Obes Rev 2015;16:942-61.

41. Röhling M, Herder C, Stemper T, et al. Influence of acute and chronic exercise on glucose uptake. J Diabetes Res 2016;2016:1-33.

42. Harmer AR, Elkins MR. Amount and frequency of exercise affect glycaemic control more than exercise mode or intensity. Br J Sports Med 2015;49:1012-4.

43. Marliss EB, Vranic M. Intense exercise has unique effects on both insulin release and its roles in glucoregulation: implications for diabetes. Diabetes 2002;51-S271-S283.

44. Nikseresht M, Agha-Alinejad H, Azarbayjani MA, et al. Effects of nonlinear resistance and aerobic interval training on cytokines and insulin resistance in sedentary men who are obese. J Strength Cond Res 2014;28:2560-8

45. Sim AY, Wallman KE, Fairchild TJ, et al. Effects of high-intensity intermittent exercise training on appetite regulation. Med Sci Sports Exerc 2015;47:2441-9.

46. UK Prospective Diabetes Study Group. Intensive blood-glucose control with sulphonylureas or insulin compared with conventional treatment and risk of complications in patients with type 2 diabetes (UKPDS 33). UK Prospective Diabetes Study (UKPDS) group. Lancet 1998;352:837-53.

47. Davey GJG, Roberts JD, Patel S. Effects of exercise on insulin resistance in South Asians and Europeans. J Exerc Physiol Online 2000;3:12-22.

48. AbouAssi $\mathrm{H}$, Slentz CA, Mikus $\mathrm{CR}$, et al. The effects of aerobic, resistance, and combination training on insulin sensitivity and secretion in overweight adults from STRRIDE AT/RT: a randomized trial. J Appl Physiol 2015;118:1474-82. 